\title{
Short- and long-term reproductive effects of prenatal and lactational growth restriction caused by maternal diabetes in male rats
}

\author{
Elaine MP Amorim", Débora C Damasceno ${ }^{2}$, Juliana E Perobelli ${ }^{3}$, Raquel Spadotto ${ }^{4}$, Carla DB Fernandez ${ }^{4}$, \\ Gustavo T Volpato ${ }^{4}$ and Wilma DG Kempinas ${ }^{4^{*}}$
}

\begin{abstract}
Background: A suboptimal intrauterine environment may have a detrimental effect on gonadal development and thereby increases the risk for reproductive disorders and infertility in adult life. Here, we used uncontrolled maternal diabetes as a model to provoke pre- and perinatal growth restriction and evaluate the sexual development of rat male offspring.

Methods: Maternal diabetes was induced in the dams through administration of a single i.v. dose of $40 \mathrm{mg} / \mathrm{kg}$ streptozotocin, 7 days before mating. Female rats presenting glycemic levels above $200 \mathrm{mg} / \mathrm{dL}$ after the induction were selected for the experiment. The male offspring was analyzed at different phases of sexual development, i.e., peripuberty, postpuberty and adulthood.

Results: Body weight and blood glucose levels of pups, on the third postnatal day, were lower in the offspring of diabetic dams compared to controls. Maternal diabetes also provoked delayed testicular descent and preputial separation. In the offspring of diabetic dams the weight of reproductive organs at 40, 60 and 90 days-old was lower, as well as sperm reserves and sperm transit time through the epididymis. However the plasma testosterone levels were not different among experimental groups.

Conclusions: It is difficult to isolate the effects directly from diabetes and those from IUGR. Although the exposure to hyperglycemic environment during prenatal life and lactation delayed the onset of puberty in male rats, the IUGR, in the studied model, did not influenced the structural organization of the male gonads of the offspring at any point during sexual development. However the decrease in sperm reserves in epididymal cauda and the acceleration in sperm transit time in this portion of epididymis may lead to an impairment of sperm quality and fertility potential in these animals. Additional studies are needed in attempt to investigate the fertility of animals with intrauterine growth restriction by maternal diabetes and possible multigenerational effects.
\end{abstract}

Keywords: developmental programming, growth restriction, male rat, maternal diabetes, puberty, sexual development

\section{Background}

Epidemiological studies and controlled experimental investigations in several species have demonstrated that impaired fetal growth is associated with long-term health effects [1-3]. In humans, a relationship between intrauterine growth restriction (IUGR) and cardiac diseases,

\footnotetext{
* Correspondence: kempinas@ibb.unesp.br

${ }^{4}$ Department of Morphology, Institute of Biosciences, UNESP - Univ Estadual Paulista, 18618-970, Botucatu, São Paulo, Brazil

Full list of author information is available at the end of the article
}

hypertension, type 2 diabetes, resistance to insulin, and obesity has been well documented, making evident the role of prenatal programming as a determinant of diseases in the adult [4-7]. However, few studies have investigated the impact of the IUGR on reproductive function $[8,9]$.

Fetal growth retardation seems to be associated with an increased risk of premature adrenarche, early puberty, polycystic ovary syndrome and associated fertility problems [10-13]. In males, prospectives studies show that

\section{() Biomed Central}


impaired intrauterine growth increases the risk of congenital hypospadias, cryptorchidism and testicular cancer approximately two- to threefold [14-16]. Although few studies focus on the effect of intrauterine growth conditions on male sexual development and sperm quality later in life, previous studies suggested an impairment of both Sertoli and Leydig cell functions [8].

Different experimental models have been used to investigate the effects of IUGR in the offspring development: exposure of dams to isocaloric diet with low protein content [17-19]; global restriction of nutrient [20]; restriction of uterine blood flow [21,22]; exposure of fetuses to elevated levels of glycocorticoids [23] and experimental induction of maternal diabetes [24-26]. Animal models of maternal diabetes during pregnancy and/or lactation or neonatal overnutrition have provided valuable insight into mechanisms involved in perinatal programming of diseases in adult life. Furthermore, numerous animal experiments have been performed to understand the epidemiological association between IUGR and subsequent disease risk.

In the present study we examined the male offspring exposed to maternal diabetes during pregnancy and lactation to determine whether growth restriction, in this experimental model, disturbs pubertal and sexual development. Animal models are necessary to clarify pathogenetic and pathophysiologic aspects of IUGR. They also make it possible to investigate short and long term effects of untreated diabetics in pregnant rats, which is not ethically possible in humans [27].

\section{Methods}

\section{Animals}

Thirty male and 74 female Wistar rats aged 30 days were supplied by the Multidisciplinary Center for Biological Investigation of the University of Campinas, CEMIB UNICAMP. The animals were adapted and maintained in the Small Mammal Biotherium of the Department of Morphology in the Institute of Biosciences at Botucatu, UNESP, where they were housed in collective polyethylene cages $(43 \times 30 \times 15)$, under controlled conditions of temperature, maintained between $22^{\circ}$ and $25^{\circ} \mathrm{C}$, relative humidity of approximately $55 \%$ and $12 \mathrm{~h}$ photoperiod (light period beginning at $0700 \mathrm{~h}$ ), with free access to water and food. At 90 days of age, the experimental period was initiated. The experimental protocol followed the Ethical Principles in Animal Experimentation adopted by the Brazilian College of Animal Experimentation (COBEA) and was approved by the Commission of Ethics in Animal Experimentation (CEEA) of the Institute of Biosciences at Botucatu (protocol 05/05).

\section{Experimental sequence for induction of diabetes in rats} At 90 days of age, diabetes was induced in 57 female rats using streptozotocin (STZ - SIGMA Chemical
Company, St. Louis, MO, USA). STZ was administered i.v. into the tail vein in a single dose of $40 \mathrm{mg} / \mathrm{kg}$ dissolved in citrate buffer $(0.1 \mathrm{M}, \mathrm{pH} 4.5)$. Control rats $(\mathrm{n}=17)$ received (i.v.) citrate buffer. Blood glucose concentrations were measured 7 days after induction of diabetes. Glycemia was determined by collecting one drop of blood of the distal part of the rat tail and depositing it in glucose oxidase reagent strips, which were read in a specific glycosimeter (One Touch Ultra - Johnson \& Johnson $\left.{ }^{\circledR}\right)$. Only rats with blood glucose levels higher than $200 \mathrm{mg} / \mathrm{dL}$ were included in the diabetic group.

\section{Natural matings and obtainment of offspring}

Eight days after administration of STZ, the estrous cycle was evaluated daily by vaginal smear and when females were in estrus phase, they were placed in the male cage and allowed to mate with non-diabetic male rats overnight (one female/male rat). In the next morning males and females were separated and gestational day zero (GD0) was determined by the presence of sperm in vaginal smears. After 15 days of mating procedure, the rats that did not present a positive pregnancy were discarded. Timed-pregnant female rats were housed individually and observed daily for delivery. For the indirect evaluation of the maternal toxicity, the rats were weighed in alternating days (from GD0 to 20), for control of weight gain. On the mornings of GD $0,7,14$ and 21 blood samples were collected for determination of maternal glycemia following the procedures utilized during the diabetogenic period. The food and water intake were also measured in alternate days.

From GD20 pregnant rats were observed for delivery that was considered as day 0 of post natal life (PND0). All rats presented spontaneous vaginal delivery. Litters with less than 8 pups or litters that were cannibalized in part or totally were discharged. Pups were not weighed at birth to prevent maternal rejection [27]. At PND3 all litters were weighed and glycemic levels were determined. The number of pups per litter was reduced to eight when necessary [28], in order to maintain, preferentially, male offspring. Two groups were established: OC (offspring of control dams) and OD (offspring of diabetic dams).

\section{Evaluation of male offspring after birth}

After weaning (PND 21) all pups were fed with control diet ad libitum and maintained in groups of up to four/ cage until puberty. The litter was utilized as the sample unit for the parameters evaluated up to PND 39. Reproductive development was evaluated at the following ages: peripuberty (PND 40), postpuberty (PND 60) and adulthood (PND90), in groups of 6 to 8 rats each, one or two per litter. Body weight and glycemic levels of offspring were evaluated at PND3, 10, 40, 60 and 90. 


\section{Evaluation of external physical signs of male sexual development (onset of puberty)}

Starting on PND15 the time of testicular descent was determined by daily palpation of the scrotal sac. Preputial separation began to be investigated on PND33 through manual retraction of the prepuce.

\section{Collection of reproductive organs}

At ages predicted, the animals were anesthetized with ethyl ether and killed by decapitation. Blood was collected from the ruptured cervical vessels for the determination of total testosterone concentration, as described below. The right testis and epididymis were removed and weighed, and in rats aged 60 and 90 days they were frozen at $-4^{\circ} \mathrm{C}$ to be processed for counting of germ cells. The seminal vesicle (full, without the coagulating gland) and ventral prostate were also removed, weighed and discarded. At different ages of sexual development, the left testis and epididymis were removed and immersed in Alfac fixative mixture (85\% alcohol $80^{\circ}, 10 \%$ formaldehyde, and 5\% acetic acid) for $24 \mathrm{~h}$. The tissues were embedded in Paraplast, sectioned at $5 \mu \mathrm{m}$ and stained with hematoxilin and eosin (HE) for evaluation of spermatogenesis and histopathological analysis.

\section{Daily sperm production per testis, sperm number and transit time in the epididymis}

The sperm concentration was estimated in rats at PND60 and 90. Homogenization-resistant testicular spermatids (stage 19 of spermiogenesis) and sperm in the caput/corpus and cauda epididymidis were enumerated as described previously by Robb et al. [29], with adaptations described by Fernandes et al.[30]: the right testis, decapsulated and weighed soon after collection, were homogenized in $5 \mathrm{ml}$ of $\mathrm{NaCl} 0.9 \%$ containing Triton $\times 1000.5 \%$, followed by sonication for $30 \mathrm{sec}$. After a 10-fold dilution a sample was transferred to Newbauer chambers (4 fields per animal), preceding a count of mature spermatids. To calculate daily sperm production (DSP) the number of spermatids at stage 19 was divided by 6.1 , which is the number of days of the seminiferous cycle in which these spermatids are present in the seminiferous epithelium. In the same manner, caput/corpus and cauda epididymidis portions were cut into small fragments with scissors and homogenized, and sperm counted as described for the testis. The sperm transit time through the epididymis was determined by dividing the number of sperm in each portion (caput/corpus and cauda) by DSP.

\section{Sperm morphology}

For the evaluation of sperm morphology, the left vas deferens of 90-day-old rats was sectioned at its extremities and washed with the aid of a syringe coupled to a needle, containing $1.0 \mathrm{~mL}$ of formol-saline solution. The washed product was collected in an Eppendorf tube and, soon after, smears were prepared in histological slides and left to dry in open air. With the aid of a phase-contrast microscope, the smears were analyzed (final magnification 200 times) and 100 sperm were evaluated per animal. Morphological abnormalities found in sperm were classified into two categories: a) head abnormalities: without characteristic curvature, in pinhead form, and isolated; b) tail abnormalities: folded, broken and isolated. Besides morphology, the presence or absence of cytoplasmic droplet in sperm was also evaluated.

\section{Evaluation of spermatogenic process and histopathological analysis}

Aiming to evaluate the dynamic of the spermatogenic process, 100 transversal sections of seminiferous tubules per animal were analyzed at PND 40, 60 and 90, utilizing the method of attribution of values, according to the most mature germ cell present in the tubular epithelium [31]. The sections were evaluated randomly and classified by the most advanced cell type present in the epithelium: score 1 - only spermatocytes; score 2 - young spermatids with round nucleus (stages 1 to 8 of spermiogenesis); score 3- spermatids in maturation phase, with ovoid or elongated nuclei (stages 9 to 14 of spermiogenesis); score 4- spermatids in maturation phase, with elongated nuclei (stages 15 to 18 of spermiogenesis); score 5 - mature spermatids (stage 19 of spermiogenesis) in small quantity; score 6- mature spermatids (stage 19 of spermiogenesis) in medium and maximum quantity. Finally, the number of tubules classified into each score of maturity was multiplied by its respective score, with the resultant values summed and then divided by 100 , resulting in a "mean score". In adult animals (90 days), a more detailed evaluation of spermatogenesis was made in seminiferous tubules, classifying them into stages of I-VI, VII-VIII, IX-XIII and $\mathrm{XIV}$, according to the number of generations of spermatids, presence of mature spermatids localized on the lumen border or secondary spermatocyte [32].

At PND 40, 60 and 90 the testes and epididymides of rats were examined under light microscope for analysis of the epithelial aspect, ductular lumen and interstitial tissue for identification of possible histopathological damage.

\section{Number of Sertoli cells per seminiferous tubule}

To evaluate the possible effects of in utero and lactational growth restriction on the process of proliferation of Sertoli cells, all the nuclei of Sertoli cells were counted in histological sections of the testis of 90-days-old rats, in 20 seminiferous tubules per rat at stage VII of spermatogenesis, classified according to Leblond and Clermont [33]. The evaluations were accomplished in a blind assay (without knowledge of the group to which each animal may belong). 


\section{Determination of plasma concentrations of total testosterone}

After the decapitation of male rats at different ages, the blood was collected from the rupture of cervical vessels in a heparinized tube for determination of plasma testosterone concentrations. The plasma was obtained by centrifugation $\left(2400 \mathrm{rpm}, 20 \mathrm{~min}, 3.5^{\circ} \mathrm{C}\right)$ and frozen at $-20^{\circ} \mathrm{C}$ until the moment of hormonal dosing. The concentrations of total plasma testosterone were determined in the Clinical Analysis Laboratory at the Botucatu Medical School, by the chemiluminescence methodology on the DPC-brand Immulit automatic equipment.

\section{Statistical evaluation of results}

For analysis of percentages between the number of pregnant females and those that presented gestation to term, the Fisher exact test was utilized and the data were expressed as a percentage. For comparison of other parameters evaluated among the experimental groups, the Student's t test or Mann-Whitney test were utilized, depending on the normal and non-normal distribution of the data, respectively. Statistical analyses were accomplished by the program Instat (version 3.0; GraphPad, Inc., San Diego, CA, USA). Data were expressed as mean \pm standard error of mean (SEM). The limit of statistical significance was considered $\mathrm{p}<0.05$.

\section{Results}

\section{Evaluation of maternal results}

The diabetic rats showed a significant increase in food and water intake when compared to control group (data not shown). The polyuria was observed due to the increase of humidity in the cage but this metabolic parameter was not measured. All rats that received STZ became diabetic $(\mathrm{n}=$ 57 ) and 55 of them had positive pregnancy. However, only $45.45 \%$ had termed pregnancy. The control group was initially composed of 17 female and all of them had positive and termed pregnancy (100\%). As the litters with less than 8 pups or litters that were cannibalized were discharged, only 7 and 12 litters were used for diabetic and control group respectively.

Diabetic rats presented lower body weight gain during pregnancy (Table 1). The length of gestation was similar between the experimental groups (data not show). Blood glycemic levels were greater than $200 \mathrm{mg} / \mathrm{dL}$ in the diabetic rats, indicating severe diabetes. Normoglycemia was observed in the control rats $(<120 \mathrm{mg} / \mathrm{dL})$ (Table 1$)$.

\section{Evaluation of male offspring after birth}

The mean body weight and glycemic levels at PND 3 were smaller in the OD compared to OC (Table 2). On the other hand, on PND10 the glycemic levels were similar between the groups (Table 2).
Pups of diabetic dams showed a significant retardation in the time of testicular descent and preputial separation. These delays in the sexual development were accompanied by reduced body weights in the OD compared to the OC (Table 3).

\section{Reproductive parameters evaluated in different phases of male sexual development}

The body weight of OD group was lower at all ages analyzed, although at 90 days of age the difference was not statistically significant (Table 4). Glycemic levels were similar between groups independent of age. The absolute weights of the testis (PND40 and 60), epididymis (PND40, 60 and 90), prostate (PND60 and 90), seminal vesicle (PND60), as well as the relative weight of the epididymis (PND60) of OD group were lower when compared to OC (Table 4).

At PND60, the number of mature spermatids and the daily sperm production in the testes of OD group were significantly lower when compared to OC. These same parameters, when analyzed in relative terms, were similar between the experimental groups (Table 5). Sperm number in the caput-corpus of the epididymis and the sperm transit time through this epididymal portion were reduced in OD compared to OC. The same parameters in epididymal cauda were similar between the two groups (Table 5). At PND90, both daily sperm production and the number of spermatids in the testis, expressed in relative terms, were greater in OD compared to OC. In the epididymis, sperm number and transit time in caput-corpus region did not differ between the experimental groups, while the sperm transit time and the number of sperm in epididymal cauda was lower in the OD group (Table 5).

Sperm morphology was similar between the groups, with both presenting $89 \%$ normal sperm and $84 \%$ of sperm showing retention of the cytoplasmic droplet, in the inferior medial third of the flagellum.

Evaluation of the spermatogenic process at different moments of reproductive development did not indicate differences $(p>0.05)$ in the mean maturation score of the seminiferous epithelium (peripuberty: $2.60 \pm 0.14,2.30 \pm$ 0.22 ; postpuberty: $3.91 \pm 0.13,3.74 \pm 0.07$; adulthood: 4.01 $\pm 0.03,4.01 \pm 0.07$, OC and OD, respectively). In the same manner, in 90-day-old animals there were no differences in the spermatogenic process and in the number of Sertoli cells between the experimental groups (Table 6).

The qualitative histopathological analysis of the testes and epididymides did not reveal any alterations that could be attributed to the exposure to hyperglycemic environment during intrauterine development and lactation (data not shown). Plasma testosterone levels in the OD were similar $(p>0.05)$ to those of the OC in all studied ages (Figure 1). 


\begin{tabular}{lcc}
\hline & Non-diabetic group $(\boldsymbol{n}=\mathbf{1 7})$ & Diabetic group $(\boldsymbol{n}=\mathbf{5 5})$ \\
\hline Body weight $(g)$ & & $219.35 \pm 3.07$ \\
GD 0 & $218.64 \pm 6.28$ & $240.06 \pm 2.93$ \\
GD 7 & $239.07 \pm 6.61$ & $262.27 \pm 3.87$ \\
GD 14 & $271.91 \pm 6.74$ & $288.40 \pm 6.27$ \\
GD 21 & $310.18 \pm 7.71$ & $69.05 \pm 4.56^{\mathrm{a}}$ \\
Maternal Gain (GD 21-GD 0) & $91.54 \pm 2.95$ & $476.86 \pm 10.06^{\mathrm{a}}$ \\
Blood glucose concentrations (mg/dL) & & $468.71 \pm 1.77^{\mathrm{a}}$ \\
GD 0 & $111.16 \pm 3.64$ & $525.48 \pm 24.47^{\mathrm{a}}$ \\
GD 7 & $106.63 \pm 3.50$ & $561.32 \pm 13.43^{\mathrm{a}}$ \\
GD 14 & $96.94 \pm 2.75$ & $84.76 \pm 3.19$ \\
\hline
\end{tabular}

Values are expressed as mean \pm SEM. ${ }^{a} \mathrm{p}<0.0001$. Mann-Whitney test. GD: gestational day.

\section{Discussion}

In the present study, the classic pathophysiological signs of Diabetes mellitus such as hyperglycemia, polyphagia, polydipsia and polyuria, and lower body-weight gain during gestation were observed in the rats eight days after induction of diabetes, corroborating other studies in rodents [34-36].

The hypoglycemia of OD at PND3 may be explained as an exacerbated response of $\beta$-pancreatic cells of these pups due to the excessive hyperglycemic stimulus received in the intrauterine environment [37-39], although other factors may be involved. Low birth weight is the main characteristic of the IUGR and occurs frequently when high doses of STZ are used to induce diabetes $[26,27,38]$. Other studies have shown a reduction in body weight in fetuses of STZ induced-diabetic dams [34,40]. Data from literature demonstrate that intrauterine growth-restricted pups remain small up to adulthood [38], corroborating the results of the present study. Cross-fostering studies have shown that neonates of diabetic dams nursed by control rats recovered body weight around the weaning [27]. On the other hand, control pups suckled by diabetic dams presented a progressive delay in growth during neonatal life, with significant decrease in body weight from PND 14 [41]. Diabetic rats present decreased synthesis and milk ejection [42], and the milk from these animals has reduced levels of lactose, fat and protein [43], which apparently led to undernutrition in the offspring from nontreated diabetic dams. This factor during lactation period probably contributed with the persistent reduction in body weight in OD pups.

The increase in the ages of testicular descent and preputial separation in OD group may suggest that IUGR, besides impairing the normal growth and development of the male offspring, provokes retardation of the initial sexual development of these animals. Others studies corroborate our results showing that early malnutrition and consequent IUGR delay the onset of puberty in rats, associated or not with a body weight reduction $[22,44,45]$. Earlier reports have clearly shown that abnormal intrauterine environment affects the development of several fetal tissues and organs postnatally [46-48]. The present findings indicate impaired growth of male reproductive organs which may be explained, at least in part, due to the low body weight presented by these animals, since these same parameters, when analyzed in relation to body weight, were not significant.

The results of the histological analyses showed that the growth restriction caused by the maternal diabetes during gestation and lactation, did not impair the structural organization of the male offspring gonads, at any point during sexual development. At PND60 the reduction in testicular and epididymal sperm counts seem to be related to the smaller weight of these organs, since they were not significant when analyzed in relation to body weight. On the other hand, in adulthood the sperm reserves in the

Table 2 Body weight and blood glucose concentrations on postnatal days 3 and 10

\begin{tabular}{lcc}
\hline & OC & OD \\
\hline Body weigth $(g)$ & $10.09 \pm 0.98(n=12)$ & $6.43 \pm 0.87^{\mathrm{a}}(\mathrm{n}=7)$ \\
PND3 & $106.83 \pm 2.00(\mathrm{n}=12)$ & $61.23 \pm 5.00^{\mathrm{a}}(\mathrm{n}=7)$ \\
Blood glucose concentrations $(\mathrm{mg} / \mathrm{dL})$ & $140.46 \pm 3.00(\mathrm{n}=12)$ & $124.94 \pm 6.00(\mathrm{n}=7)$ \\
PND3 & \\
PND10
\end{tabular}

Values expressed as mean \pm SEM. ${ }^{a} p<0.05$. Student's t-test.

OC - litters from control rats; OD - litters from diabetic dams 
Table 3 Ages and weights of the litters on the days of testicular descent and preputial separation

\begin{tabular}{lcc}
\hline & OC (12 litters) & OD (7 litters) \\
\hline Testicular descent (days) & $19.93 \pm 0.19$ & $22.89 \pm 0.44^{\mathrm{a}}$ \\
Weight (g) of pups at the day of testicular descent & $44.92 \pm 1.12$ & $23.07 \pm 2.85^{\mathrm{b}}$ \\
Preputial separation (days) & $42.83 \pm 0.39$ & $45.13 \pm 0.36^{\mathrm{a}}$ \\
Weight (g) of pups at the day of preputial separation & $150.73 \pm 3.24$ & $96.48 \pm 7.62^{\mathrm{a}}$ \\
\hline
\end{tabular}

Values expressed as mean \pm SEM. ${ }^{\mathrm{a}} \mathrm{p}<0.05^{\mathrm{b}} \mathrm{p}<0.01$. Mann-Whitney test. OC - litters from control rats; OD - litters from diabetic dams

epididymal cauda were diminished independently of body weight reduction. Animals born from mothers exposed to protein restriction during gestation, another model of IUGR, showed a reduction in sperm reserves in adulthood, corroborating the result of the present study [49].

As a consequence of the decrease in sperm reserves in the cauda, the sperm transit time was accelerated in this epididymal region. The sperm transit time is a process regulated by androgens, which control the viscosity of epididymal luminal fluid and the contractility of the duct [50]. Other factors such as adrenergic, cholinergic, nonadrenergic noncholinergic innervation [51] and angiotensins, vasopressins and ocytocins in the blood [52] may act in the contractility of epididymal duct, interfering in the sperm transit. The accelerated transit of sperm through the epididymis promotes lower exposure of the gametes to the epididymal microenvironment which is crutial to the processes of sperm maturation [53,54]. Since plasma testosterone levels did not differ between male offspring of control and diabetic dams in the present study, the alteration of sperm transit time through the epididymis appears to have been independent of androgen action.

Recently, a clear relationship between low birth weight and adult renal disease has been stablished, probably related to the reduction of nephron endowment. Data in the literature suggests that individuals with IUGR have $70 \%$ greater risk of developing chronic kidney disease in adulthood $[55,56]$. Considering that epididymis and kidney structures have a common embrionary origin from
Wolffian ducts [57] these results on renal diseases associated to IUGR may indicate a possible impairment on epididymal development and function at adulthood. Future studies are necessary to investigate the responsible mechanisms for this modification of sperm transit time through the epididymis and the possible consequences on sperm quality.

Nowadays, concern regarding intergenerational studies is well stablished, not only due to genetic factors but also to epigenetic mechanisms [58]. Burdge and co-authors [59] showed that alterations in the methylation status in specific genes of rat pups (F1) exposed to protein restriction during pregnancy can be transferred to subsequent generations, assuring the importance of epigenetic mechanisms. More investigations are necessary to evaluate the multigenerational effects of in utero and lactational exposure to a hyperglycemic environment.

\section{Conclusions}

In conclusion, it is difficult to isolate the effects directly from diabetes and those from IUGR. Although the exposure to hyperglycemic environment during prenatal life and lactation delayed the onset of puberty in male rats, the IUGR, in the studied model, did not influenced the structural organization of the male gonads of the offspring at any point during sexual development. However the decrease in sperm reserves in epididymal cauda and the acceleration in sperm transit time in this portion of epididymis may lead to an impairment of sperm quality

Table 4 Body weight, glycemia, absolute and relative weights of the male reproductive organs of rats at 40, 60 and 90 days old

\begin{tabular}{|c|c|c|c|c|c|c|}
\hline & \multicolumn{2}{|c|}{40 days } & \multicolumn{2}{|c|}{60 days } & \multicolumn{2}{|c|}{90 days } \\
\hline & $O C(n=8)$ & $O D(n=6)$ & $O C(n=8)$ & $O D(n=6)$ & $O C(n=6)$ & $O D(n=6)$ \\
\hline Body weight (g) & $148.89 \pm 4.40$ & $102.90 \pm 5.17^{b}$ & $269.14 \pm 9.54$ & $219.38 \pm 10.45^{a}$ & $375.76 \pm 6.70$ & $314.48 \pm 25.46$ \\
\hline Glycemia (mg/dL) & $132.25 \pm 12.18$ & $142.33 \pm 11.40$ & $109.00 \pm 3.71$ & $113.67 \pm 2.94$ & $103.00 \pm 2.37$ & $103.00 \pm 0.39$ \\
\hline Testis $(g)$ & $0.69 \pm 63.78$ & $0.44 \pm 49.10^{a}$ & $1.50 \pm 0.05$ & $1.12 \pm 0.05^{b}$ & $1.63 \pm 0.15$ & $1.39 \pm 0.10$ \\
\hline$(g / 100 \mathrm{~g}$ of $\mathrm{BW})$ & $0.46 \pm 29.60$ & $0.42 \pm 35.08$ & $0.56 \pm 0.02$ & $0.52 \pm 0.04$ & $0.44 \pm 0.05$ & $0.45 \pm 0.02$ \\
\hline Epididymis (mg) & $74.51 \pm 6.44$ & $49.50 \pm 4.30^{b}$ & $271.56 \pm 7.08$ & $172.73 \pm 13.92^{b}$ & $532.92 \pm .92$ & $423.70 \pm 28.32^{b}$ \\
\hline$(\mathrm{mg} / 100 \mathrm{~g}$ of $\mathrm{BW})$ & $49.74 \pm 2.96$ & $48.15 \pm 0.74$ & $100.85 \pm 5.26$ & $80.13 \pm 7.95^{\mathrm{a}}$ & $143.17 \pm 7.18$ & $135.64 \pm 2.73$ \\
\hline Prostate (mg) & $51.60 \pm 5.74$ & $40.98 \pm 2.58$ & $167.30 \pm 1.22$ & $112.70 \pm 9.06^{\mathrm{a}}$ & $429.72 \pm 9.25$ & $278.88 \pm 14.95^{b}$ \\
\hline$(\mathrm{mg} / 100 \mathrm{~g}$ of $\mathrm{BW})$ & $34.43 \pm 3.54$ & $40.08 \pm 2.65$ & $60.37 \pm 5.07$ & $51.84 \pm 4.46$ & $115.04 \pm 7.96$ & $91.23 \pm 7.34$ \\
\hline S. vesicle (mg) & $28.58 \pm 5.51$ & $20.88 \pm 2.71$ & $432.63 \pm 4.36$ & $260.82 \pm 38.65^{a}$ & $1120.00 \pm 0.08$ & $853.00 \pm 0.10$ \\
\hline$(\mathrm{mg} / 100 \mathrm{~g}$ of $\mathrm{BW})$ & $18.24 \pm 3.03$ & $20.41 \pm 2.59$ & $156.32 \pm 3.58$ & $123.76 \pm 26.25$ & $298.30 \pm 0.02$ & $275.25 \pm 0.03$ \\
\hline
\end{tabular}

Values expressed as mean \pm SEM. ${ }^{a} \mathrm{p}<0.05^{\mathrm{b}} \mathrm{p}<0.01$. Mann-Whitney test. BW- body weight. OC- offspring of control dams; OD- offspring of diabetic dams. 
Table 5 Sperm counts in rats at 60 and 90 days-old.

\begin{tabular}{|c|c|c|c|c|}
\hline & \multicolumn{2}{|c|}{60 days } & \multicolumn{2}{|c|}{90 days } \\
\hline & $O C(n=8)$ & $O D(n=6)$ & $O C(n=6)$ & $O D(n=6)$ \\
\hline \multicolumn{5}{|l|}{ Testis } \\
\hline $\begin{array}{l}\text { Daily sperm production } \\
\left(\times 10^{6}\right) / \text { testis }\end{array}$ & $24.38 \pm 0.77$ & $17.05 \pm 1.70^{b}$ & $38.08 \pm 0.85$ & $34.50 \pm 1.81$ \\
\hline $\begin{array}{l}\text { Daily sperm production } \\
\left(\times 10^{6}\right) / g \text { of testis }\end{array}$ & $20.98 \pm 0.45$ & $20.85 \pm 1.26$ & $24.65 \pm 0.69$ & $29.52 \pm 1.15^{a}$ \\
\hline $\begin{array}{l}\text { Number of spermatids } \\
\left(\times 10^{6}\right) / \text { testis }\end{array}$ & $148.70 \pm 4.70$ & $104.00 \pm 10.38^{b}$ & $232.27 \pm 5.16$ & $210.62 \pm 11.13$ \\
\hline $\begin{array}{l}\text { Number of spermatids } \\
\left(\times 10^{6}\right) / \mathrm{g} \text { of testis }\end{array}$ & $127.97 \pm 2.72$ & $127.16 \pm 7.67$ & $150.60 \pm 0.30$ & $180.23 \pm 6.97^{b}$ \\
\hline \multicolumn{5}{|l|}{ Caput/corpus epididymis } \\
\hline Sperm number $\left(\times 10^{6}\right)$ & $59.71 \pm 6.71$ & $25.77 \pm 6.21^{\mathrm{b}}$ & $112.63 \pm 6.90$ & $92.03 \pm 7.40$ \\
\hline Sperm number $\left(\times 10^{6}\right) / \mathrm{g}$ of epididymal region & $401.33 \pm 30.55$ & $279.41 \pm 47.69^{\mathrm{a}}$ & $365.95 \pm 13.88$ & $386.60 \pm 14.23$ \\
\hline Sperm transit time (days) & $2.04 \pm 0.21$ & $1.47 \pm 0.67^{\mathrm{a}}$ & $2.97 \pm 0.17$ & $2.65 \pm 0.15$ \\
\hline \multicolumn{5}{|l|}{ Cauda epididymis } \\
\hline Sperm number $\left(\times 10^{6}\right)$ & $27.07 \pm 5.68$ & $10.66 \pm 5.10$ & $188.08 \pm 5.34$ & $137.80 \pm 10.55^{b}$ \\
\hline Sperm number $\left(\times 10^{6}\right) / \mathrm{g}$ of epididymal region & $353.56 \pm 53.11$ & $249.18 \pm 97.29$ & $1024.25 \pm 0.28$ & $840.37 \pm 26.67^{b}$ \\
\hline Sperm transit time (days) & $1.07 \pm 0.20$ & $0.54 \pm 0.18$ & $4.95 \pm 0.15$ & $4.09 \pm 0.26^{\mathrm{a}}$ \\
\hline
\end{tabular}

Values expressed as mean \pm SEM. ${ }^{a} p<0.05,{ }^{b} p<0.01$. Student's t-test. OC- offspring of control dams; OD- offspring of diabetic dams.

Table 6 Seminiferous epithelium cycle and mean number of Sertoli cells per seminiferous tubule of 90-day-old animals.

\begin{tabular}{lcc}
\hline & OC $(\mathbf{n}=\mathbf{5})$ & OD $(\mathbf{n}=\mathbf{5})$ \\
\hline Stages of the germinal epithelium & & $39.75 \pm 1.32$ \\
I-VI & $41.75 \pm 0.75$ & $31.00 \pm 1.15$ \\
VII-VIII & $28.75 \pm 1.49$ & $24.5 \pm 1.44$ \\
IX-XIII & $24.75 \pm 0.48$ & $4.75 \pm 0.48$ \\
XIV & $4.75 \pm 0.85$ & $14.33 \pm 0.18$ \\
Mean number of Sertoli cells & $14.70 \pm 0.15$ & \\
\hline
\end{tabular}

Values expressed as mean \pm SEM. Student's t-test. OC- offspring of control dams; OD - offspring of diabetic dams.

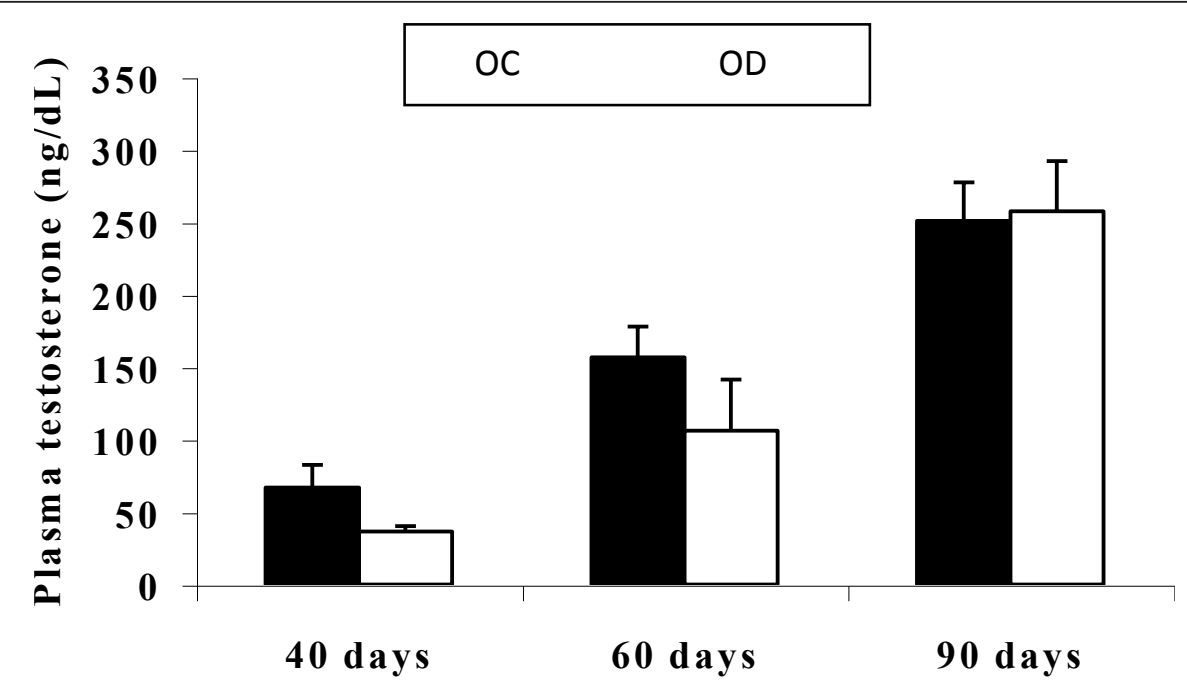

Figure 1 Testosterone levels. Plasma testosterone levels in the animals at the age 40 days $(O C, n=5 ; O D, n=5), 60$ days $(O C, n=7 ; O D, n=$ 6) and 90 days (OC, $n=11 ; O D, n=8)$. OC: offspring of control dams; OD: offspring of diabetic dams. Values expressed as mean \pm SEM. Student's t-test. 
and fertility potential in these animals. Additional studies are needed in attempt to investigate the fertility of animals with intrauterine growth restriction by maternal diabetes and possible multigenerational effects.

\author{
Acknowledgements \\ This work was supported by The State of São Paulo Research Foundation \\ (Fapesp).
}

\section{Author details}

${ }^{1}$ Center of Biological and Health Sciences (CCBS), State University of West Paraná (UNIOESTE), Cascavel, Paraná, Brazil. ²Department of Gynecology and Obstetrics, Botucatu Medical School, UNESP - Univ Estadual Paulista, Botucatu, São Paulo, Brazil. ${ }^{3}$ Graduate Program in Cell and Structural Biology, Institute of Biology, University of Campinas, Campinas, São Paulo, Brazil. ${ }^{4}$ Department of Morphology, Institute of Biosciences, UNESP - Univ Estadual Paulista, 18618-970, Botucatu, São Paulo, Brazil.

\section{Authors' contributions}

All authors participated in the design, interpretation of the studies, analysis of the data and review of the manuscript; EMPA, DCD, JEP, RS, CDBF and GTV conducted the experiments; EMPA and WDGK wrote the manuscript. This study represents EMPA's Masters Thesis presented to the State University of Campinas, under the advisory of WDGK. All authors read and approved the final manuscript.

\section{Competing interests}

The authors declare that they have no competing interests.

Received: 12 August 2011 Accepted: 6 December 2011 Published: 6 December 2011

\section{References}

1. Bautista CJ, Boeck L, Larrea F, Nathanielsz PW, Zambrano E: Effects of a maternal low protein isocaloric diet on milk leptin and progeny serum leptin concentration and appetitive behavior in the first 21 days of neonatal life in the rat. Pediatr Res 2008, 63(4):358-363.

2. Ojeda NB, Grigore D, Alexander BT: Intrauterine growth restriction: fetal programming of hypertension and kidney disease. Adv Chronic Kidney Dis 2008, 15(2):101-106.

3. Eriksson JG, Forsén TJ, Kajantie E, Osmond C, Barker DJ: Childhood growth and hypertension in later life. Hypertension 2007, 49(6):1415-1421.

4. Thapar A, Harold G, Rice F, Ge X, Boivin J, Hay D, Van Den Bree M, Lewis A: Do intrauterine or genetic influences explain the foetal origins of chronic disease? A novel experimental method for disentangling effects. BMC Med Res Methodol 2007, 22:7-25.

5. Hng TM, Cheung NW, MCLean M: Growth hormone and cortisol dynamic function in relation to birth weight: a study in adult twins. J Clin Endocrinol Metab 2005, 90(5):2781-2786.

6. Boloker J, Gertz SJ, Simmons RA: Gestational diabetes leads to the development of diabetes in adulthood in the rat. Diabetes 2002, 51(5):1499-1506

7. Barker DJ, Clark PM: Fetal undernutrition and disease in later life. Rev Reprod 1997, 2(2):105-112.

8. Main KM, Jensen RB, Asklund C, Hoi-Hansen CE, Skakkebaek NE: Low birth weight and male reproductive function. Horm Res 2006, 65(3):116-122.

9. Ibáñez L, Ferrer A, Marcos MV, Hierro FR, de Zegher F: Early puberty: rapid progression and reduced final height in girls with low birth weight. Pediatrics 2000, 106(5):E72.

10. Ibáñez L, Jaramillo A, Enríquez G, Miró E, López-Bermejo A, Dunger D, de Zegher F: Polycystic ovaries after precocious pubarche: relation to prenatal growth. Hum Reprod 2007, 22(2):395-400.

11. van Weissenbruch MM: Premature adrenarche, polycystic ovary syndrome and intrauterine growth retardation: does a relationship exist? Curr Opin Endocrinol Diabetes Obes 2007, 14(1):35-40.

12. Guzmán C, Cabrera R, Cárdenas M, Larrea F, Nathanielsz PW, Zambrano E: Protein restriction during fetal and neonatal development in the rat alters. J Physiol 2006, 572(1):97-108.
13. Bruin JP, Dorland M, Bruinse HW, Spliet W, Nikkels PGJ, Te Velde ER: Fetal growth retardation as a cause of impaired ovarian development. Early Hum Dev 1998, 51(1):39-46.

14. Fujimoto T, Suwa T, Kabe K, Adachi T, Nakabayashi M, Amamiya T: Placental insufficiency in early gestation is associated with hypospadias. J Pediatr Surg 2008, 43(2):358-361.

15. Gatti JM, Kirsch AJ, Troyer WA, Perez-Brayfield MR, Smith EA, Scherz HC: Increased incidence of hypospadias in small-for-gestational age infants in a neonatal intensive-care unit. BJU Int 2001, 87(6):548-550.

16. Weir HK, Marrett LD, Kreiger N, Darlington GA, Sugar L: Pre-natal and perinatal exposures and risk of testicular germ-cell cancer. Int J Cancer 2000, 87(3):438-443.

17. Zambrano E, Bautista CJ, Deás M, Martínez-Samayoa PM, GonzálezZamorano M, Ledesma H, Morales J, Larrea F, Nathanielsz PW: A low maternal protein diet during pregnancy and lactation has sex- and window of exposure-specific effects on offspring growth and food intake, glucose metabolism and serum leptin in the rat. J Physiol 2006, 571(1):221-230.

18. Zambrano E, Rodríguez-González GL, Guzmán C, García-Becerra R, Boeck L, Díaz L, Menjivar M, Larrea F, Nathanielsz PW: A maternal low protein diet during gestation and lactation in the rat male reproductive development. J Physiol 2005, 563(1):275-284.

19. Zambrano E, Martínez-Samayoa PM, Bautista CJ, Deás M, Guillén L, Rodríguez-González GL, Guzmán C, Larrea F, Nathanielsz PW: Sex differences in transgenerational alterations of growth and metabolism in progeny (F2) of female offspring (F1) of rats fed a low protein diet during gestation and lactation. J Physiol 2005, 566(1):225-236.

20. Garofano A, Czernichow P, Bréant B: In utero undernutrition impairs rat beta-cell development. Diabetologia 1997, 40(10):1231-1234.

21. Simmons RA, Templeton $\sqcup$, Gertz SJ: Intrauterine growth retardation leads to the development of type 2 diabetes in rat. Diabetes 2001, 50(10):2279-2286.

22. Engelbregt MJ, Houdijk ME, Popp-Snijders C, Delemarre-van de Waal HA: The effects of intrauterine growth retardation and postnatal undernutrition on onset of puberty in male and female rats. Pediatr Res 2000, 48(6):803-807.

23. Lesage J, Del-Favero F, Leonhardt M, Louvart H, Maccari S, Vieau D, Darnaudery M: Prenatal stress induces intrauterine growth restriction and programmes glucose intolerance and feeding behaviour disturbances in the aged rat. J Endocrinol 2004, 181(2):291-296.

24. Neitzke U, Harder T, Schellong K, Melchior K, Ziska T, Rodekamp E, Dudenhausen JW, Plagemann A: Intrauterine growth restriction in a rodent model and developmental programming of the metabolic syndrome: a critical appraisal of the experimental evidence. Placenta 2008, 29(3):246-254.

25. Holemans K, Van Bree R, Verhaeghe J, Meurrens K, Van Assche FA: Maternal semistarvation and streptozotocin-diabetes in rats have different effects on the vivo glucose uptake by peripheral tissues in their female adult offspring. J Nutr 1997, 127(7):1371-1376.

26. Holemans K, Gerber RT, Meurrens K, De Clerck F, Poston L, Van Assche FA: Streptozotocin diabetes in the pregnant induces cardiovascular dysfunction in adult offspring. Diabetologia 1999, 42(1):81-89.

27. Holemans K, Aerts L, Van Assche FA: Fetal Growth restriction and consequences for the offspring in animal models. I Soc Gynecol Investig 2003, 10(7):392-399.

28. Chahoud I, Paumgartten FJ: Influence of litter size on the postnatal growth of rat pups: Is there a rationale for litter-size standardization in toxicity studies? Environ Res 2009, 109(8):1021-1027.

29. Robb GW, Amman RP, Killian GJ: Daily sperm production and epididymal sperm reserves of pubertal and adult rats. J Reprod Fertil 1978, 54(1):103-107.

30. Fernandes GS, Arena AC, Fernandez CD, Mercadante A, Barbisan LF, Kempinas WG: Reproductive effects in male rats exposed to diuron. Reprod Toxicol 2007, 23(1):106-112.

31. Carvalho TL, Guimaraes MA, Kempinas WG, Petenusci SO, Rosa e Silva AA: Effects of guanethidine-induced sympathectomy on the spermatogenic and steroidogenic testicular functions of pre-pubertal to mature rats. Andrologia 1996, 28(2):117-122.

32. Ferreira $A L$, Lison $L$, Valeri $V$ : Caryometric study of spermatogenesis in the rat. Z Zellforsch Mikrosk Anat 1967, 76(1):31-55. 
33. Leblond $C P$, Clermont Y: Definition of the stages of the cycle of the seminiferous epithelium in the rat. Ann N Y Acad Sci 1952, 55(4):548-573.

34. Al Ghafli MH, Padmanabhan R, Kataya HH, Berg B: Effects of a-lipoid acid supplementation on maternal diabetes-induced growth retardation and congenital anomalies in rat fetuses. Mol Cell Biochem 2004, 261(12):123-135.

35. Damasceno DC, Volpato GT, de Mattos Paranhos Calderon I, Cunha Rudge MV: Oxidative stress and diabetes in gestation rats. Anim Reprod Sci 2002, 72(3-4):235-244

36. Padmanabhan R, Al-Zuhair AG: Congenital malformations and intrauterine growth retardation in streptozotocin induced diabetes during gestation in rat. Reprod Toxicol 1998, 1(2):117-125.

37. Holemans K, Aerts L, Van Assche FA: Lifetime consequences of abnormal fetal pancreatic development. J Physiol 2003, 547(1):11-20.

38. Van Assche FA, Holemans K, Aerts L: Long-term consequences for offspring of diabetes during gestation. Br Med Bull 2001, 60:173-182.

39. Han J, Xu J, Long YS, Epstein PN, Liu YQ: Rat maternal diabetes impairs pancreatic beta-cell function in the offspring. Am J Physiol Endocrinol Metab 2007, 293(1):E228-236.

40. Kobayashi A, Ueda Y, Morikawa H, Mochizuki M: Effects of maternal hyperglycemia on fetal growing mechanism. Nihon Sanka Fujinka Gakkai Zasshi 1991, 43(3):289-296.

41. Fahrenkrog S, Harder T, Stolaczyk E, Melchior K, Franke K, Dudenhausen JW, Plagemann A: Cross-fostering to diabetic rat dams affects early development of mediobasal hypothalamic nuclei regulating food intake, body weight, and metabolism. J Nutr 2004, 134(3):648-654.

42. Lau C, Sullivan MK, Hazelwood RL: Effects of diabetes mellitus on lactation in the rat. Proc Soc Exp Biol Med 1993, 204(1):81-89.

43. Neubauer SH: Lactation in insulin-dependent diabetes. Prog Food Nutr Sci 1990, 14(4):333-370.

44. Léonhardt M, Lesage J, Croix D, Dutriez-Casteloot I, Beauvillain JC, Dupouy JP: Effects of perinatal maternal food restriction on pituitarygonadal axis and plasma leptin levels in rat pup at birth and weaning and on timing of puberty. Biol Reprod 2003, 68(2):390-400.

45. Engelbregt MJ, Van Weissenbrunch MM, Popp-Snijders C, Lips P, Delemarrevan de Waal HA: Body mass index, body composition, and leptin at onset of puberty in male and female rats after intrauterine growth retardation and after early postnatal food nutrition. Pediatr Res 2001, 50(4):474-478.

46. Canavan JP, Holt J, Goldspink DF: The effects of established diabetes on the growth of the fetal liver and skin in the rat. Comp Biochem Physiol Comp Physiol 1992, 102(3):547-552.

47. Amri K, Freund N, Vilar J, Merlet-Bénichou C, Lelièvre-Pégorier M: Adverse effects of hyperglycaemia on kidney development in rats: in vivo and in vitro studies. Diabetes 1999, 48(11):2240-2245.

48. Bourbon JR, Pignol B, Marin L, Rieutort M, Tordet C: Maturation of fetal rat lung in diabetic pregnancies of graduated severity. Diabetes 1985 34(8):734-743.

49. Toledo FC, Perobelli JE, Pedrosa FP, Anselmo-Franci JÁ, Kempinas WD: In utero protein restriction causes growth delay and alters sperm parameters in adult male rats. Reprod Biol Endocrinol 2011, 9:94.

50. Sujarit S, Pholpramool C: Enhancement of sperm transport through the rat epididymis after castration. J Reprod Fertil 1985, 74(2):497-502.

51. Ricker DD, Crone JK, Chamness SL, Klinefelter GR, Chang TS: Partial sympathetic denervation of the rat epididymis permits fertilization but inhibits embryo development. J Androl 1997, 18(2):131-138.

52. Cooper TG: Epididymis. In Encyclopedia of Reproduction. Volume 2. Edited by: Knobil E, Neill JD. California: Academic Press; 1998:1-17.

53. Persson I, Ahlsson F, Ewald U, Tuvemo T, Qingyuan M, von Rosen D, Proos L: Influence of perinatal factors on the onset of puberty in boys and girls: implications for interpretation of link with risk of long term diseases. Am J Epidemiol 1999, 150(7):747-755.

54. Bhargava SK, Ramji S, Srivastava U, Sachdev HP, Kapani V, Datta V, Satyanarayana L: Growth and sexual maturation of low birth weight children: a 14 year follow up. Indian Pediatr 1995, 32(9):963-970.

55. White SL, Perkovic V, Cass A, Chang CL, Poulter NR, Spector T, Haysom L, Craig JC, Salmi IA, Chadban SJ, Huxley RR: Is low birth weights an antecedent of CDK in latter life? A systematic rewiew of observational studies. Am J Kidney Dis 2009, 54:248-261.

56. Lim K, Lombardo P, Schneider-Kolsky M, Hilliard L, Denton KM, Black MJ: Induction of hyperglycemia in adult intrauterine growth-restricted rats: effects on renal function. Am J Physiol Renal Physiol 2011, 301(2): F288-F294.

57. Rodríguez CM, Kirby $J$, Hinton BT: The development of the epididymis. In The Epididymis - from molecules to clinical practice.. 1 edition. Edited by: Robaire B, Hinton BT. New York: Kluwer Academic/Plenum Publisher; 2002:251-268.

58. Petry CJ, Desai M, Ozanne SE, Hales CN: Early and late nutritional windows for diabetes susceptibility. Proc Nutr Soc 1997, 56:233-242.

59. Burdge GC, Slater-Jefferies J, Torrens C, Phillips ES, Hanson MA, Lillycrop KA: Dietary protein restriction of pregnant rats in the Fo generation induces altered methylation of hepatic gene promoters in the adult male offspring in the F1 and F2 generations. Br J Nutr 2007, 97(3):435-439.

doi:10.1186/1477-7827-9-154

Cite this article as: Amorim et al:: Short- and long-term reproductive effects of prenatal and lactational growth restriction caused by maternal diabetes in male rats. Reproductive Biology and Endocrinology $20119: 154$

\section{Submit your next manuscript to BioMed Central and take full advantage of:}

- Convenient online submission

- Thorough peer review

- No space constraints or color figure charges

- Immediate publication on acceptance

- Inclusion in PubMed, CAS, Scopus and Google Scholar

- Research which is freely available for redistribution

Submit your manuscript at www.biomedcentral.com/submit
Biomed Central 